\section{Resolutions of the NCTE}

At their annual convention in Baltimore in November 1989, members of the National Council of Teachers of English passed the following resolutions:

\section{On students' freedom of speech and press}

BACKGROUND: The NCTE members who proposed this resolution pointed to recent court actions which have reduced students' rights to free speech and free press. They cited the Hazelwood decision, in which the U.S. Supreme Court ruled that school administrators may censor student newspapers, magazines, and performances on grounds of "legitimate pedagogical concerns." The proposers pointed out that the Hazelwood decision allows state laws to take precedence over the Supreme Court ruling, thus criating an opportunity for proponents of free speech to defend students' rights.

RESOLVED, that the National Council of Teachers of English urge state legislators, state departments of education, and local school districts to promote legislation protecting the rights of students in their exercise of freedom of speech and press; that NCTE urge and assist its affiliates to promote legislation ensuring these rights; and that NCTE urge all local communities and schools to ensure these rights.

\section{On testing young children}

BACKGROUND: NCTE members who proposed this resolution pointed out that children in preschool and primary grades now face increasing numbers of norm-referenced, multiple-choice, standardized tests given to determine achievement levels, potential learning problems, and readiness for school. They warned however, the results of such tests can be misinterpreted if children's inexperience with test-taking and test formats is not taken into account.

Further, the members said, scores on standardized tests reflect neither the diversity of children's preschool experiences nor the range of their development. Nevertheless, test results may be used to assign young children to curricular tracks. Their use of scores by school boards, administrators, and teacher committees, the proposers said, prompts teachers to replace sound educational practices with undesirable efforts to prepare children merely to take tests.

RESOLVED, that the National Council of Teachers of English urge legislatures, state departments of education, and local school districts to end immediately the use of normreferenced, multiple-choice, standardized tests for children in preschool and the primary grades; and that NCTE urge state and local affiliates to educate state legislators, administrators and other officials, and parents about the powerful and dangerous impact these tests can have on the development and education of young children.

\section{On national assessment of educational progress and the assessment of reading}

BACKGROUND: NCTE members who proposed this resolution observed that if a reader is to get meaning from a text, the reader needs a flexible repertoire of strategies, including ways of deciphering individual words. But the members warned of potential dangers if word identification skills are included in instruments for large-scale assessment of students' educational progress. They warned that because what is tested tends to govern what is taught, assessing word identification skills on mass tests could encourage schools to place undue emphasis on such skilis in the classroom. As a result, word identification, "a means of facilitating reading," could become an end in itself. The proposers noted that recent assessments by NAEP suggest that over-emphasis on "lowlevel" skills may be subverting broader educational goals.

RESOLVED, that the National Council of Teachers of English affirm the NAEP's current practice of assessing comprehension in reading; that NCTE urge the NAEP not to incorporate the testing of discrete word identification skills into assessments conducted by the NAEP; and that NCTE intensify efforts to inform educators, policymakers, and the public about the problems inherent in the testing of discrete skills.

\section{On alternative routes to teacher certification}

BACKGROUND: Proposers of this resolution noted the recent resurgence of interest in 
improving teacher education, which has produced a number of reform proposals, most of them calling for additional formal preparation for future teachers. They pointed out that even while legislating higher standards for teacher education, 25 states have created alternative, less demanding routes to certification. The proposers voiced concern that alternative routes often bypass important aspects of professional education, and in effect produce on-the-job training for teachers.

RESOLVED, that the National Council of Teachers of English affirm the importance of the kinds of knowledge, pedagogy, and attitudes represented in the 1986 Guidelines for the Preparation of Teachers of English Language Arts; that NCTE affirm that individuals who assume full responsibility for English/ language arts instruction must be prepared by professional programs of teacher education emphasizing the kinds of knowledge, pedagogy, and attitudes represented in the Guidelines; and that NCTE encourage its affiliates to monitor the legislative developments affecting teacher certification and to educate state legislators and other officials about the importance of professional teacher education.

\section{On identifying authors of instructional materials}

BACKGROUND: Proposers of this resolution called attention to educational publishers' practice of listing as authors the names of educators who have made little or no contribution to the materials. These NCTE members pointed out that the actual authors of many textbooks are from publishers' in-house editorial staff. With increasing frequency, they noted, texts are written by "development houses" - corporations that contract with freelance writers and editors to produce text. The proposers asserted that this practice raises issues of ethics and accuracy within the publishing world and the education community.

RESOLVED, that the National Council of Teachers of English urge publishers to identify the actual authors of their instructional materials and to detail as fully as possible the contributions of consultants; that NCTE urge all groups involved in the adoption process, particularly teachers and administrators, to demand that publishers identify the authors of instructional materials and detail the contributions of consultants; and that NCTE urge educators to refuse to be cited as authors of instructional materials if they have not written a significant part of these materials.

\section{On textbook selection procedures}

BACKGROUND: NCTE members who proposed this resolution observed that the textbooks selected for use in the nation's classrooms have a powerful influence on curriculum in the schools. They stressed that the teachers who use these books are uniquely qualified to judge their strengths and weaknesses as instructional materials.

RESOLVED, that the National Council of Teachers of English reaffirm that all bookselection decisions be based upon soundly developed criteria.

(The above information was sent to us by DIANE ALLEN, who can be contacted at the National Council of Teachers of English, 1111 Kenyon Road, Urbana, Illinois 61801, USA.) 